\title{
Toward a comprehensive global electric circuit model: Atmospheric conductivity and its variability in CESM1(WACCM) model simulations
}

\author{
A. J. G. Baumgaertner, ${ }^{1,2}$ J. P. Thayer, ${ }^{1}$ R. R. Neely III, ${ }^{3}$ and G. Lucas ${ }^{1}$ \\ Received 13 May 2013; revised 26 July 2013; accepted 8 August 2013; published 28 August 2013.
}

[1] As an important step in further modeling and understanding the global electric circuit, the Community Earth System Model (CESM1) has been extended to provide a calculation of conductivity in the troposphere and stratosphere. Conductivity depends on ion mobility and ion concentration, the latter being controlled by a number of ion production and loss processes. This leads to a complex dependency of conductivity on most importantly galactic cosmic ray flux, radon emissions from the Earth's surface, aerosol number concentrations, clouds, and temperature. To cover this variety in parameters for calculating and evaluating conductivity, an Earth system model is extremely useful. Here the extension of CESM1 to calculate conductivity is described, and the results are discussed with a focus on their spatial and temporal variabilities. The results are also compared to balloon and aircraft measurements, and good agreement is found for undisturbed conditions and during a solar proton event. The conductivity model implementation is a significant improvement to previous studies because of the high-quality, high-resolution model data input. Notably, the aerosol representation provided by off-line calculations of tropospheric and stratospheric aerosol using the Community Aerosol and Radiation Model for Atmospheres as part of CESM1(WACCM) (Whole Atmosphere Community Climate Model) provides a realistic computation of the impact of the background aerosol distribution for the first time. In addition to the novel high-resolution information on conductivity, it is found that an intra-annual cycle exists in the total global resistance, varying between 220 and $245 \Omega$. The model shows that this cycle is driven equally by seasonal aerosol and cloud variations.

Citation: Baumgaertner, A. J. G., J. P. Thayer, R. R. Neely III, and G. Lucas (2013), Toward a comprehensive global electric circuit model: Atmospheric conductivity and its variability in CESM1(WACCM) model simulations, J. Geophys. Res. Atmos., 118, 9221-9232, doi:10.1002/jgrd.50725.

\section{Introduction}

[2] Atmospheric electricity research is one of the earliest atmospheric research fields, beginning most notably in the eighteenth century with Benjamin Franklin's experiments on lightning. The ionosphere is held at a constant positive potential of approximately $250 \mathrm{kV}$ with respect to the ground because thunderstorms and other electrified clouds charge the ionosphere predominantly by currents (known as Wilson currents) and also by electrodynamic

\footnotetext{
${ }^{1}$ Department of Aerospace Engineering Sciences, University of Colorado Boulder, Boulder, Colorado, USA.

${ }^{2}$ High Altitude Observatory, National Center for Atmospheric Research, Boulder, Colorado, USA.

${ }^{3}$ Atmospheric Chemistry Division, National Center for Atmospheric Research, Boulder, Colorado, USA.

Corresponding author: A. J. G. Baumgaertner, Department of Aerospace Engineering Sciences, University of Colorado Boulder, ECNT 320, 431 UCB, Boulder, CO 80309-0429, USA. (work@andreas-baumgaertner.net)

(C)2013. American Geophysical Union. All Rights Reserved. 2169-897X/13/10.1002/jgrd.50725
}

events (sprites and elves). A fair-weather current density of approximately $1 \mathrm{pA} / \mathrm{m}^{2}$ discharges the ionosphere, closing the global electric circuit (GEC) and globally maintaining a current flow of $1-2 \mathrm{kA}$.

[3] The field of atmospheric electricity encompasses DC (direct current) and $\mathrm{AC}$ (alternating current) phenomena. There are numerous reviews of the GEC as well as reviews focusing on various aspects. Detailed presentations can be found in Krider [1986], especially chapters 11-15, and more recently in Leblanc et al. [2008], which contains a collection of articles published in Space Science Reviews, including a historical review [Aplin et al., 2008]. Numerous short reviews have been presented in the literature [e.g., Singh et al., 2004; Rycroft and Harrison, 2012; Rycroft et al., 2012]. For a recent summary on AC phenomena and aspects, refer to, e.g., Pasko [2010].

[4] The current flow through the lower and middle atmosphere is possible because electrically charged constituents make the atmosphere sufficiently conductive $\left(10^{-15}-10^{-7} \mathrm{~S} / \mathrm{m}\right)$ to create electrical pathways for currents to flow between the Earth's surface, clouds, and the ionosphere. 
The distribution of conductivity is critical to advancing the understanding of how the GEC flows, closes, and potentially impacts other aspects of Earth's climate system. The conductivity is determined by the number density of charged molecules and their mobility through the atmosphere. The mobility of charge is strongly dependent on the density of the atmosphere's neutral gas, and so the mobility increases with height as the neutral gas density decreases exponentially. The number density of charged particles is dependent on production and loss processes from various sources through the atmosphere. Production of charge is attributed to ionization processes due largely to galactic cosmic rays (GCRs) and nuclear decay from gases at the Earth's surface. Losses of charge occur through recombination of positive and negative ions and attachment of ions to aerosol particles or cloud droplets. These disparate production and loss processes have a dynamic interplay in the atmosphere that lead to large uncertainty in estimates of conductivity and its distribution about the globe.

[5] It is possible to directly measure most of the parameters associated with the GEC [Nicoll, 2012]. In particular, measurements exist of ionospheric potential, electric fields, currents, and conductivity (see reviews listed above for a description of the measurement techniques and results). In addition, measurements of ion production rate (for a review, see Bazilevskaya et al. [2008]), ion-loss processes, and ion mobility [Rosen et al., 1985] have been performed. This has led to a basic appreciation of many GEC aspects.

[6] From basic electrodynamic principles it is possible to calculate the potential distribution, currents, and electric fields given only a current source distribution and conductivity. An analytical solution to this was presented by Hays and Roble [1979] and Roble and Hays [1979a, 1979b] using basic assumptions for sources and conductivity. In the last 10 years, progress was achieved by combining existing measurements to form comprehensive models of the GEC. Using commercially available software for electrical engineering, Rycroft et al. [2007] and Rycroft and Odzimek [2009, 2010] derived currents and ionospheric potential. However, uncertainties in the source currents and conductivity, as well as limitations in the applied solution techniques, still remain.

[7] For conductivity, a more comprehensive picture than that obtained from measurements has been derived from calculations based on measurements of other atmospheric quantities. Estimates of conductivity based on measured GCR ionization rates, published ion recombination rates, and mobility approximations have been compared to conductivity measurements for several decades. Detailed work taking into account the influence of aerosols, clouds, and radioactive decay of substances emitted from the Earth's surface was presented by Tinsley and Zhou [2006], TZ06 hereafter, and Zhou and Tinsley [2010], ZT10 hereafter. Both TZ06 and ZT10 used available measurements of GCRs, aerosol distributions, and clouds for their conductivity model. The aerosol data were based on the GADS (Global Aerosol Data Set) database and assumed size distributions. The cloud information originated from the International Satellite Cloud Climatology Project (ISCCP), which only provides data during daylight conditions. The calculated conductivity data were employed in further studies by other authors, e.g., for the potential calculations in Odzimek et al. [2010]. Here we greatly enhance the work by TZ06 and ZT06 by calculating conductivity using an Earth System Model framework that provides consistent temperatures, cloud cover, aerosol size distributions, and radon distributions including its transport by winds and convection. This allows for an unprecedented global and time-varying calculation of conductivity with high resolution in both time and space. While the data will be of great importance to calculating other aspects of the GEC with potential solvers, it requires a comparison with existing measurements and allows for several new scientific insights, as presented in this study.

[8] Note that we will not address conductivity inside thunderstorms in this study. Thunderstorms are believed to be the main driver of the GEC, but conductivity inside the cloud is still controversially debated; see MacGorman and Rust [1998, chapters 7.5 and 7.6] for a literature discussion.

[9] The CESM1 model and the conductivity module extensions are described in section 2. Results gained from model simulations performed with CESM1 are presented in section 3, including the spatial and temporal variability and other characteristics of conductivity, resistance, and parameters relevant for these. Section 3.1 compares the model results with available measurements. Finally, a summary and conclusions are presented in section 4 .

\section{Model Description}

\subsection{CESM1}

[10] The Community Earth System Model (CESM1) is a fully coupled, global climate model that provides state-of-the-art computer simulations of the Earth's past, present, and future climate states. For the present study we applied the model version CESM1.1 using an atmospheric horizontal resolution of $1.9^{\circ}$ by $2.5^{\circ}$ in latitude and longitude, respectively. The employed component set (F_1955-2005_WACCM_CN) uses the Whole Atmosphere Community Climate Model (WACCM), with prescribed sea surface temperatures and ice coverage, and the Community Land Model (CLM). The source code, documentation, and input data sets for the model are freely available from the CESM1 website (www.cesm.ucar.edu). A detailed model description is given by Marsh et al. [2013]. CESM1 can be operated as a free-running model or nudged toward a reanalysis data set to match winds and temperature observations. For the work presented here the model was free running. With respect to the vertical resolution, the employed component set operates on 66 vertical levels up to approximately $140 \mathrm{~km}$. Because of the exponential pressure decrease with altitude, the levels are spaced accordingly, which is also well suited for the calculation of the exponentially decreasing conductivity and derived quantities such as column resistance.

[11] For calculating conductivity, size-dependent aerosol distributions are also required. The Community Aerosol and Radiation Model for Atmospheres (CARMA, version 3.0) [Turco et al., 1979; Toon et al., 1988, 1979] is a multidimensional, multisectional aerosol microphysical model capable of simulating the full aerosol life cycle, including nucleation, condensational growth, coagulation, and deposition and generally uses $22-36$ size bins. CARMA coupled to various versions of CAM and WACCM has been used to simulate many aerosol types and emission scenarios (e.g., smoke 
[Matichuk et al., 2008], stratospheric sulfate [English et al., 2011; Neely et al., 2013], wind-blown dust [Su and Toon, 2009], sea salt [Fan and Toon, 2011], noctilucent clouds [Bardeen et al., 2010], and meteoritic smoke [Bardeen et al., 2008; Neely et al., 2011]).

[12] For application to the GEC, a full representation of the size distributions of all tropospheric and stratospheric aerosols is needed. Online calculations of the size distributions of all types of aerosol needed here is computationally prohibitive; therefore, we have employed several off-line model runs to prescribe the necessary aerosol properties within the GEC module. Online aerosol calculations are possible and may be explored in future studies.

[13] For tropospheric aerosol calculations, CARMA was coupled with CAM5 (Community Atmosphere Model, version 5.0, Meehl et al. [2013]). Accordingly, the tropospheric aerosol are modeled on a $4^{\circ}$ by $5^{\circ}$ horizontal resolution grid with 30 levels from the surface to approximately $3 \mathrm{hPa}$. In this representation, CARMA includes carbonaceous aerosol (organic carbon and black carbon), wind-blown dust following $\mathrm{Su}$ and Toon [2011], and sea salt following Fan and Toon [2011]. Secondary organic aerosol does not evolve within CARMA but follows its own bulk aerosol treatment that considers semivolatile secondary organic particle concentrations as estimated by CAM5chem [Lamarque et al., 2012] using gas/particle partitioning theory developed by Pankow [1994] and further extended by Odum et al. [1996]. This mass is then spread across the calculated total aerosol size distributions, according to the suggestion of Matichuk et al. [2008]. In this model, the amount of emissions of aerosol constituents including primary organic aerosol, secondary organic aerosol, black carbon, sea salt, and dust sulfate is representative of the year 2000 .

[14] For realistic treatment of stratospheric aerosol sulfate (sources including carbonyl sulfide and natural and anthropogenic sulfur dioxide) and meteoritic smoke (a global source in the model represented by mass entering into the smallest aerosol bin between 75 and $110 \mathrm{~km}$ ), CARMA was coupled to WACCM3 as described by Neely et al. [2011, 2013]. The stratospheric aerosol conditions are representative of surface emissions of sulfur in the year 2000 and the moderate volcanic loading of 2006, which includes modeled volcanic emissions of Soufriere Hills and Tavurvur. Soufriere Hills and Tavurvur were chosen to assess the impact of moderate volcanic activity on the GEC (as opposed to colossal volcanic activity exemplified by Mount Pinatubo in 1991) as they produced the highest loading observed from 2000 to 2010 [Vernier et al., 2011a].

[15] Features added to CESM1 to calculate conductivity are described in the next subsection.

\subsection{The Conductivity Module}

[16] Conductivity, $\sigma$, is a function of ion pair concentrations, $n$, and positive/negative ion mobilities, $\mu^{+/}$, and is given by

$$
\sigma=n e\left(\mu^{+}+\mu^{-}\right)
$$

where $e$ is the elementary charge, and positive and negative ion concentrations are assumed to be equal.

[17] In the current version, the conductivity module considers the following ion sources:
[18] 1. Galactic cosmic rays (GCRs). GCRs consist of highly energetic particles, mainly protons, electrons, and helium nuclei, and originate from supernovae [Ackermann et al., 2013]. Increasing solar activity leads to a stronger interplanetary magnetic field, which allows less GCRs to penetrate the heliosphere [Usoskin et al., 2005]. The Earth's magnetic field blocks GCRs below the geomagnetic cutoff rigidity, and because the cutoff rigidity depends on magnetic latitude, more GCRs enter the atmosphere near the magnetic poles. In the lower and middle atmosphere they are the dominant source of ions, reaching a maximum production rate between 10 and $15 \mathrm{~km}$ [see, e.g., Bazilevskaya et al., 2008]. For this study, the parameterization for ion pair production incorporated into CESM1 for this study follows that of TZ06 and takes into account altitude, geomagnetic latitude, and solar activity. The employed parameterization of TZ06 was derived using data from Neher [1967, 1971].

[19] 2. Solar energetic particles. Solar flares and coronal mass ejections are eruptions on the sun's surface that lead to vastly increased fluxes of high-energy particles. Depending on the position of the Earth relative to the ejection, the particles can reach the Earth's atmosphere. The phenomenon is then called a solar proton event. A solar proton event leads to enhanced ionization in the middle and upper atmosphere and consequently to chemical changes through the production of $\mathrm{HO}_{\mathrm{x}}$ and $\mathrm{NO}_{\mathrm{y}}$ [Funke et al., 2011; Jackman and McPeters, 2004] and also causes highly increased conductivity in the polar stratosphere. The altitude profile of the ionization rate is mainly determined by the type and number of precipitating particles and their energy distributions and is readily available from the solar proton event module in CESM1 with daily resolution [Jackman et al., 2008]. Additionally, for ionization rates more detailed in space and time, the AIMOS (Atmosphere Ionization Module OSnabrueck) data, described by Wissing and Kallenrode [2009], can be employed. This data set provides a $2 \mathrm{~h}$ time resolution.

[20] 3. Natural radioactivity. Direct $\alpha, \beta, \gamma$ radiation from the Earth's land surface and decay of radioactive gases exhaled from the ground, especially radon, lead to an ionization rate of approximately 10 ion pairs $\mathrm{cm}^{-3} \mathrm{~s}^{-1}$ over land between $60^{\circ} \mathrm{S}$ and $60^{\circ} \mathrm{N}$ and half of that between $60^{\circ} \mathrm{N}$ and $70^{\circ} \mathrm{N}$. Ice and snow prevent radon from escaping into the atmosphere, and thus the ionization rate is scaled with snow fraction as well as land fraction. Note that the radon isotope ${ }^{222} \mathrm{Rn}$, which has a longer lifetime, is treated separately as described in the next paragraph. For a detailed description, see Hoppel et al. [1986].

[21] 4. Radon. The radon isotope ${ }^{222} \mathrm{Rn}$ originates from uranium and has a half-life of 3.8 days decaying to ${ }^{218}$ Po and further to ${ }^{214} \mathrm{~Pb}$. A global measurement database of monthly ${ }^{222} \mathrm{Rn}$ emissions was taken from Schery and Wasiolek [1998]. The source and decay process are solved analytically as described by Jöckel et al. [2010]. The tracer ${ }^{222} \mathrm{Rn}$ is advected by the CESM1 atmospheric model component, such that the ionization source is not only in the regions that emit the gas; e.g., it is also over water near the coasts. Modeled ${ }^{222} \mathrm{Rn}$ mass mixing ratios for 7 September from a free-running simulation is depicted in Figure 1, where the surface mass mixing ratio (right) shows pronounced enhancements due to horizontal transport northwest of the Australian continent. Vertical transport, especially through convection, can lead to enhanced concentrations in the lower 


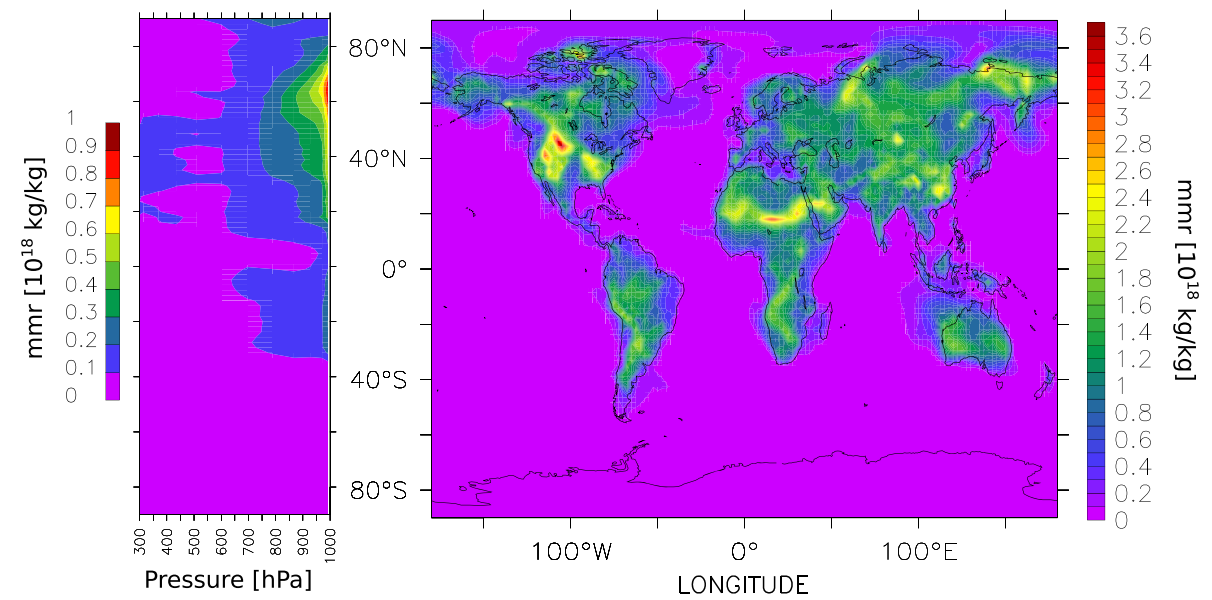

Figure 1. ${ }^{222} \mathrm{Rn}$ mass mixing ratios for 7 September from a free-running simulation of CESM1(WACCM). (left) Zonal average vertical distribution; (right) horizontal distribution in lowest model layer.

troposphere, as shown in Figure 1 (left). An evaluation of the modeled radon distributions is not presented here because the source distribution and decay algorithm are the same as those employed by Jöckel et al. [2010]. In this study, the modeled radon ${ }^{222} \mathrm{Rn}$ were compared to observations, and reasonable agreement was found. While differences due to wind transport characteristics as well as model spatial resolutions will exist between the model of Jöckel et al. [2010] and CESM1, an evaluation of the ${ }^{222} \mathrm{Rn}$ concentrations would not lead to qualitatively new results.

[22] The relative importance of the different ionization sources for the total ionization rates changes with altitude, latitude, and time. Figure 2 shows the total global mean ionization rate, neglecting any solar energetic particle events, as a function of altitude (black line) during solar maximum. The individual sources are shown in terms of their minimum and maximum contributions. The green area shows the range of GCR variability during solar maximum in space (geomagnetic latitude) and time (dashed line for solar minimum), which dominates most of the vertical behavior of the mean ionization rate. Variability of ${ }^{222} \mathrm{Rn}$ is indicated by the blue area. Below $800 \mathrm{hPa},{ }^{222} \mathrm{Rn}$ dominates the total ionization rate, can reach 28 ions $\mathrm{cm}^{-3} \mathrm{~s}^{-1}$, and exponentially decreases with altitude as expected [see, e.g., Harrison et al., 2010]. Solar proton event ionization rate altitude profiles depend on the energy distribution of the particle precipitation and are extremely variable but generally do not reach the troposphere.

[23] The red lines indicate the ionization rates from two strong solar particle events (SPEs), the Halloween storm in 2003 (solid line) and the January 2005 storm (dashed), where ionization rates of 10,000 ions $\mathrm{cm}^{-3} \mathrm{~s}^{-1}$ were reached [Wissing and Kallenrode, 2009].

[24] Ion loss occurs from ion-ion recombination. Additionally, ion attachment to aerosol particles [Hoppel, 1985] reduces their mobility drastically, essentially representing a loss process in terms of conductivity. The ion-aerosol attachment rate is therefore treated as an ion-loss rate. Clouds, where ions attach to droplets, have a similar effect on conductivity. The model representation of these three loss processes is described below.
[25] The ion-ion recombination, $\alpha$, is implemented as an altitude-dependent function of temperature and atmospheric number density as described by TZ06.

[26] Ion attachment to aerosol particles requires realistic and transient information on aerosol number density. Because of the extremely large variability of aerosol distributions caused by natural and anthropogenic emissions and atmospheric transport, a prescription of source distributions and model calculations of aerosol microphysics and transport are of great benefit for GEC descriptions. Comprehensive size-dependent aerosol distributions are provided from off-line calculations utilizing the two CARMA

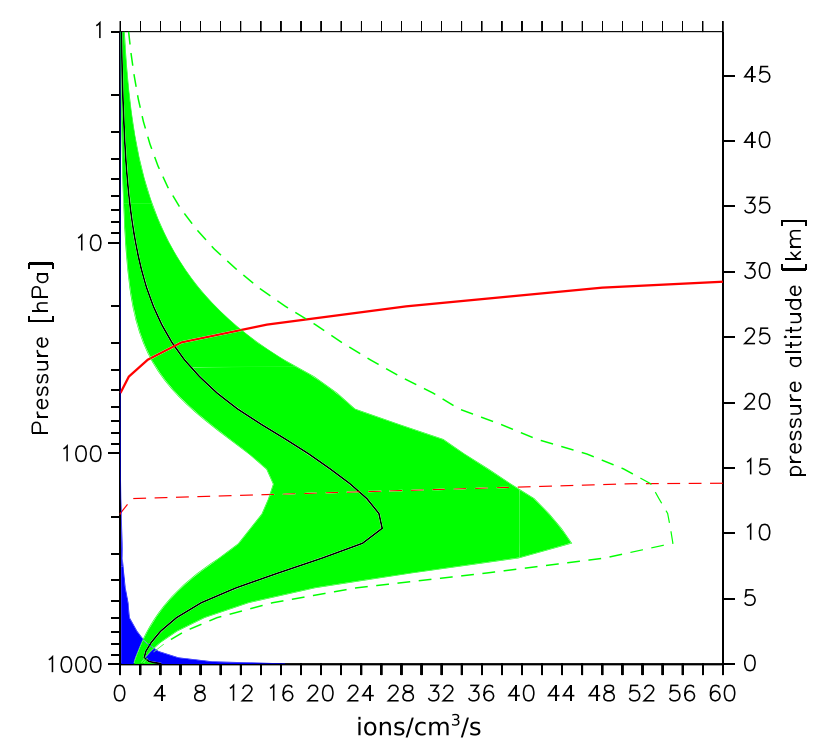

Figure 2. Mean total ionization rate (black line) and variability (filled areas) of GCRs (green, solid for solar maximum, dashed for solar minimum) and ${ }^{222} \mathrm{Rn}$ (blue) ionization, as well as solar proton event ionization rate during the Halloween storm 2003 (red solid) and January 2005 storm (red dashed). The ionization rates go off scale and reach 10,000 ions $\mathrm{cm}^{-3} \mathrm{~s}^{-1}$. 


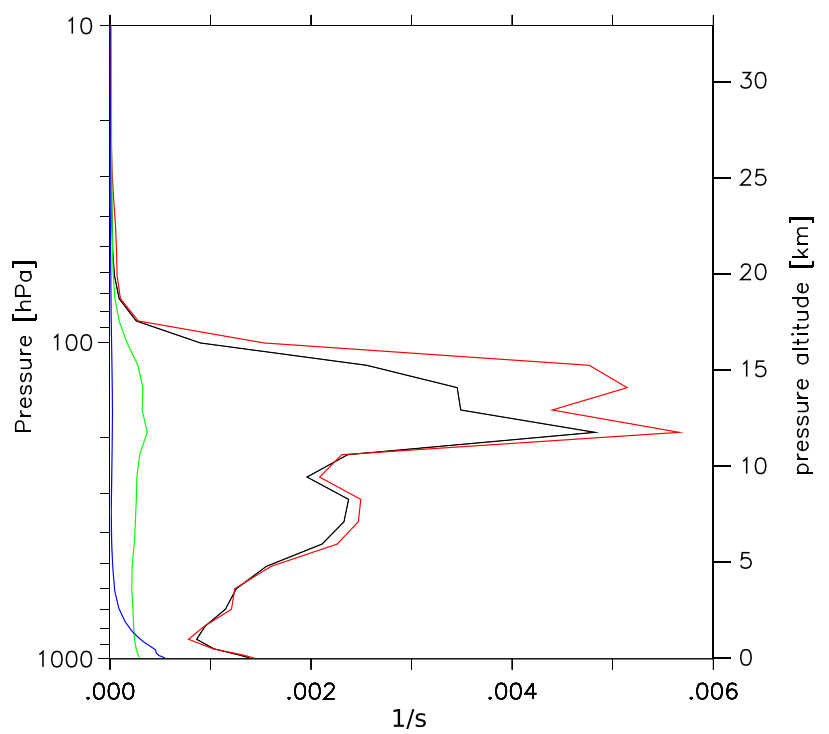

Figure 3. Ion-loss rates from aerosol. Global mean loss rates from sulfate aerosol and meteoritic dust (green). Loss rates with/without volcanic aerosol for Southeast Asia $\left(95 \pm 15^{\circ} \mathrm{E}, 10 \pm 5^{\circ} \mathrm{N}\right)$ for average August conditions (red/black). Global mean loss rate due to tropospheric aerosol excluding sulfates (blue).

models as described above. The monthly mean global distribution of radii (which was calculated as the wet radii in order to account for aerosol swelling impacts) and total number of aerosol particles in each of CARMA's bins for 1 year are used in the calculations below.

[27] The ion-aerosol attachment rate can then be calculated as

$$
\sum_{i} \sum_{r} \beta\left(r_{i}\right) S(i, r)
$$

where $S(i, r)$ is number concentration of the aerosol of type $i$, and $r$ is the particle radius. The coefficient $\beta$ is a function of particle radius. We use the same functions as TZ06; for $r>0.01 \mu \mathrm{m}$,

$$
\beta=4.36 \times 10^{-5} r-9.2 \times 10^{-8} \mathrm{~cm}^{3} \mathrm{~s}^{-1},
$$

and for $r \leq 0.01 \mu \mathrm{m}$,

$$
\beta=10^{1.243 \log _{10}(r)-3.978},
$$

where $r$ is radius in $\mu \mathrm{m}$. Note that the radii can be different for different aerosol populations; therefore, $\beta=\beta\left(r_{i}\right)$.

[28] The resulting ion-loss rates are depicted in Figure 3 for several types of aerosol. The global mean loss rate from sulfate and meteoritic dust (green), as well as from all tropospheric aerosol except for sulfate (blue), is small but increases by an order of magnitude when concentrations in aerosol increase significantly as over Southeast Asia during the Asian monsoon (black, average August conditions). Volcanic aerosol, based on the background emission scenario described in section 2, can increase lower stratospheric loss rates further (red). It should be noted that volcanoes increase the loss rate in both the troposphere and stratosphere.
[29] The ion concentration can then be calculated from the total ionization rate $q$, the ion-ion recombination rate $\alpha$, and the effective loss of ions by aerosol particles with rate $\sum_{i} \sum_{r} \beta\left(r_{i}\right) S(i, r)$ :

$$
\frac{\mathrm{d} n}{\mathrm{~d} t}=q-\alpha n^{2}-n \sum_{i} \sum_{r} \beta\left(r_{i}\right) S(i, r) .
$$

If steady state $\mathrm{d} n / \mathrm{d} t=0$ is assumed, the solution for ion concentration is

$$
n=\frac{\sqrt{4 \alpha q+\left(\sum_{i, r} \beta\left(r_{i}\right) S(i, r)\right)^{2}}-\sum_{i, r} \beta\left(r_{i}\right) S(i, r)}{2 \alpha} .
$$

[30] Cloud particles also absorb ions through both diffusion and conduction [Pruppacher and Klett, 1997]. The effects of weakly electrified clouds can be described based on their ice and liquid droplet number concentrations and radii. Inside of clouds, equation (5) then becomes

$$
\frac{\mathrm{d} n}{\mathrm{~d} t}=q-\alpha n^{2}-n \sum_{i, r} \beta\left(r_{i}\right) S(i, r)-4 \pi D n \sum_{r} N_{r} A_{r},
$$

where $N_{r}$ is the cloud droplet concentration, $A_{r}$ the droplet radius, and $D$ is ion diffusivity given by

$$
D=\frac{\mu k T}{e}
$$

[31] The atmospheric component of CESM1 provides the effective radius of ice and liquid droplets for stratiform clouds as well as their number concentrations [Morrison and Gettelman, 2008]. Similar to ZT10, using gamma distributions to calculate droplet size spectra, described in detail by Pruppacher and Klett [1997, chapter 2], the ioncloud attachment rate $4 \pi D \sum_{r} N_{r} A_{r}$ for equation (7) can be approximated.

[32] However, ZT10 showed that simply assuming a loss of conductivity by a factor of approximately 60 , rather than explicitly calculating the ion-loss rate, leads to very similar results, such that the authors concluded that the errors from other assumptions are larger and that this parameterization is a valid approximation. In this study, this approximation was reevaluated using data from CESM1 simulations, showing a large variability in the conductivity loss with values of up to $1 / 300$ inside the clouds, with some dependence on latitude and cloud altitude. An average loss of 1/50 for clouds below $440 \mathrm{hPa}$ was found, which agrees well with the finding of ZT10. Therefore, in this study we use the parameterization of ZT10 and implement cloud effects on conductivity as a loss of conductivity to $1 / 60$ in all types of clouds except deep convective clouds. The latter are strongly electrified, such that conductive attachment would also need to be considered. Due to the small contribution of deep convective clouds to overall cloud cover, the effect of these clouds is neglected for the present study.

[33] Note that CESM1 is used as a climate model in the CMIP process for IPCC, with cloud cover being crucial for climate predictions [e.g., Neale et al., 2013; Marsh et al., 2013]. The model reproduces both the observed total cloud cover and the regional distribution measured by satellites very well [Kay et al., 2012]. This is an important feature because of the strong impact of clouds on conductivity and derived GEC properties. 


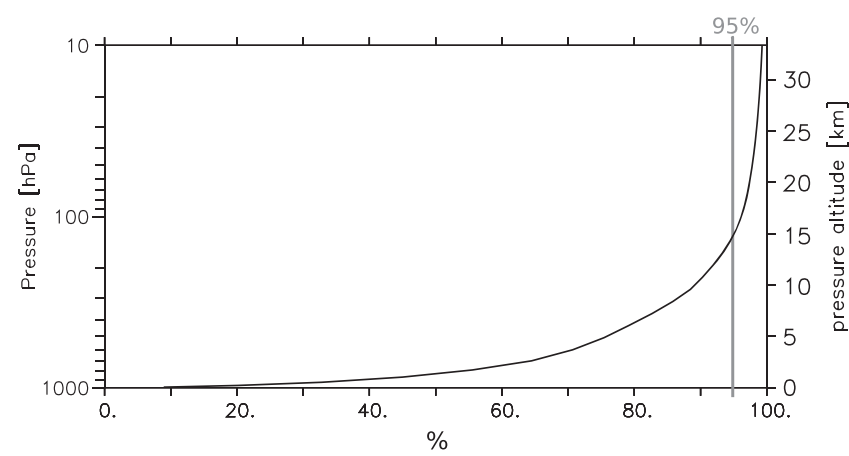

Figure 4. Column resistance contribution of conductivity as a function of altitude, in percent.

[34] Following TZ06, mobility is parameterized in the model as

$$
\mu=\mu_{0}\left(p_{0} / p\right)\left(T / T_{0}\right)
$$

where $\mu_{0}$ is the "reduced mobility" determined experimentally in clean air and $\mathrm{p}_{0}$ and $\mathrm{T}_{0}$ are for STP (standard temperature and pressure, $1013 \mathrm{hPa}$ and $273 \mathrm{~K}$ ). Although experimental difficulties lead to large uncertainties [Gringel et al., 1986], as TZ06, we use a value of $3.3 \mathrm{~cm}^{2} \mathrm{~V}^{-1} \mathrm{~s}^{-1}$ for the sum of the positive and negative ion mobilities.

[35] Finally, conductivity is calculated as described above in equation (1). Note that the WACCM model component also includes the ionosphere, where conductivity becomes a tensor. Here we only consider conductivity of the neutral atmosphere and thus limit the model calculation of conductivity to the troposphere and stratosphere below $1 \mathrm{hPa}$.

[36] Further useful quantities, derived from conductivity profiles, are column resistance and total global resistance. Column resistance is defined as the vertical integral of the reciprocal of conductivity:

$$
R_{c}=\int_{\text {surface }}^{60 \mathrm{~km}} \frac{1}{\sigma(z)} \mathrm{d} z,
$$

where $\mathrm{d} z$ are the model layer thicknesses, which depend on height and geographic location.

[37] Because of the exponential decrease of $1 / \sigma(z)$ with altitude, conductivity in the lower atmosphere largely determines column resistance. The percent contributions of global conductivity as a function of altitude are depicted in Figure 4, calculated from model results averaged over 1 year and the entire globe. It is evident that conductivity below $100 \mathrm{hPa}$ contributes over $95 \%$ of the total column resistance, justifying the upper limit of $60 \mathrm{~km}$ in equation (10). This highlights the importance of lower atmospheric ionization sources, such as ${ }^{222} \mathrm{Rn}$, and sinks, such as clouds, and will be further discussed in the following section.

[38] The total resistance is

$$
R_{\mathrm{tot}}=\left(\iint \frac{r^{2} \cos (\lambda) \mathrm{d} \phi \mathrm{d} \lambda}{R_{c}(\phi, \lambda)}\right)^{-1}
$$

where $r$ is the Earth's radius and $\mathrm{d} \phi$ and $\mathrm{d} \lambda$ are the model longitude and latitude grid sizes, respectively.

\section{Results and Discussion}

[39] The vertical profile of global mean conductivity averaged over one simulation year is shown in Figure 5 (black line). As expected, the near-exponential increase with altitude is evident, with different gradients in the troposphere and stratosphere. In section 2 it was shown that numerous factors contribute to variability of conductivity. Ion mobility (equation (9)) as well as ion recombination (equation (6) of TZ06) depend on temperature in a complex way. The gray area in Figure 5 depicts the variability of conductivity when ignoring aerosol and clouds, thus taking into account only GCR, temperature, and radon variability, the latter affecting only the lower troposphere. The radon contribution leads to an enhanced variation in conductivity (up to $200 \%$ ) near the surface. In the free troposphere between 300 and $700 \mathrm{hPa}$, conductivity varies by only about $40-50 \%$, increasing again in the stratosphere up to $100 \%$. Locally, aerosol (blue) and clouds (red) can decrease conductivity by up to 2 orders of magnitude as shown by the shaded area indicating minimum conductivity when taking into account the respective ion-loss mechanisms. Near the surface, below $800 \mathrm{hPa}$, clouds and aerosol can have similar contributions to ion loss, but the maximum aerosol-induced ion loss decreases to approximately $40 \%$ at higher altitudes.

[40] Figure 6 shows a vertical cross section of conductivity at a longitude of $30^{\circ} \mathrm{E}$ on 27 March, 0 UTC. The increase in GCR ionization toward the geomagnetic poles results in an increase in conductivity toward high geographic latitudes. Temperature variations lead to further conductivity variability (equation (9) and TZ06 equation (6)) with respect to latitude. The contours in Figure 6 depict cloud fraction at levels of $20 \%, 60 \%$, and $100 \%$ for the same time and longitude, indicating that the distinct reductions in tropospheric conductivity are related to cloud-induced losses of ions. In the lower troposphere, further decreases related to aerosol are found.

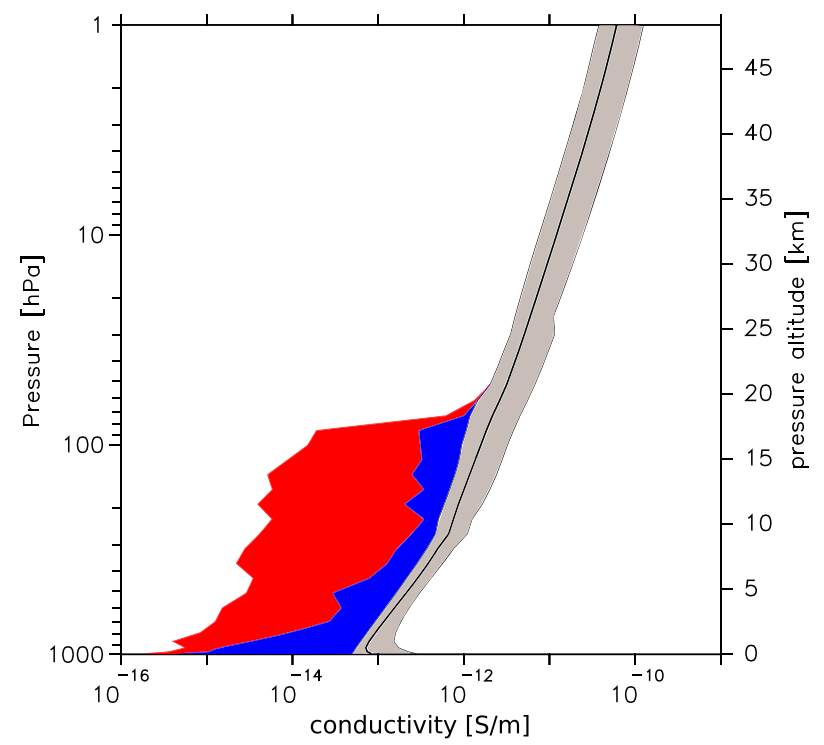

Figure 5. Mean model global conductivity profile (black) and variability (shaded gray) without clouds and aerosol. Variability when including aerosol (shaded blue). Variability when including clouds (shaded red). 


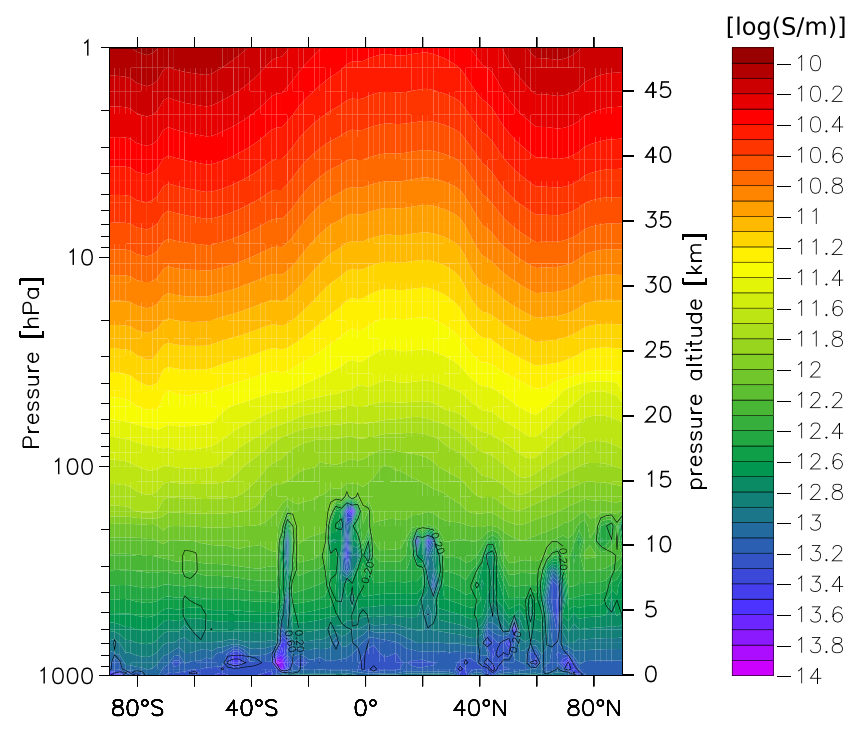

Figure 6. Model conductivity at $30^{\circ} \mathrm{E}$ longitude, 27 March, 0 UTC. Cloud fraction (black contours) $(20 \%, 60 \%$, $100 \%$ ) for the same longitude and time.

[41] Column resistance averaged over one entire model year at solar maximum, i.e., GCR minimum, is shown in Figure 7. If clouds are neglected, as shown in the left panel of Figure 7, the influence of several factors controlling conductivity and column resistance can be distinguished. In mountainous regions, such as the Himalayas, column resistance (see equation (10)) is reduced by up to $60 \%$ because GCR ionization rates increase with altitude above sea level and thus increase surface conductivity. The increase of GCR ionization at high geomagnetic latitudes reduces column resistance toward the geomagnetic poles. Aerosol production by biomass burning in Africa and strong sea salt and phytoplankton aerosol emissions lead to a decrease in ion concentration, which increases column resistance. This is clearly discernible in the updraft region of central Africa over the Atlantic ocean (i.e., the intertropical convergence zone). Even more pronounced is the influence of anthropogenic aerosol in Southeast Asia. This region is particularly important because the seasonal Asian monsoon lifts aerosolrich air masses from the lower troposphere toward the tropopause, creating the Asian Tropopause Aerosol Layer [Vernier et al., 2011b]. This is important to note, as local sources of aerosol may seasonally have a large regional, and possibly global, impact on the total conductivity of the atmosphere.

[42] Figure 7 (right) includes the effect of clouds, which lead to a strong increase in column resistance (note the different color scales). For example, over the south Atlantic and Pacific Oceans as well as northwest of the coast of South America cloud coverage increases column resistance by a factor of 3 to 5 .

[43] Several of the parameters controlling conductivity have a seasonal cycle, most importantly aerosol distributions, clouds, and temperature. Locally, this can lead to strong seasonal variations in column resistance. The absolute value of the percent change between summer and winter (June-July-August and December-January-February averages) column resistance is depicted in Figure 8. The complex interaction between variability in temperature, ${ }^{222} \mathrm{Rn}$ surface emissions, clouds, and aerosol leads to a diverse picture of summer-winter differences. Generally, seasonal variability is smallest over the oceans far away from the coasts but also over North and West Africa. Larger variability tends to show aerosol influences, especially over India where the monsoon seasonal cycle leads to a strong seasonal cycle in column resistance.

[44] In addition to the geographical variations, total resistance (see equation (11)) is subject to significant intra-annual variations. Figure 9 depicts several aspects of intra-annual variations of total resistance. Total global mean resistance (black), taking into account all of the described factors of variability including clouds and aerosol, averages to $\approx 215 \Omega$ in December and January and reaches $\approx 235 \Omega$ in July and August, an increase of nearly $10 \%$. This intra-annual variation has not been observed or modeled before. Only ZT10 suggested that aerosol intra-annual variations lead to differences between July and December total resistance.

[45] The intra-annual variation can be explained by examining total resistance contributions of aerosol, clouds, and the two hemispheres as shown in Figure 9. The red line depicts total resistance, neglecting ion loss by aerosol particles and clouds. Only a very small intra-annual change of $1 \Omega$, due to the higher global mean temperature in
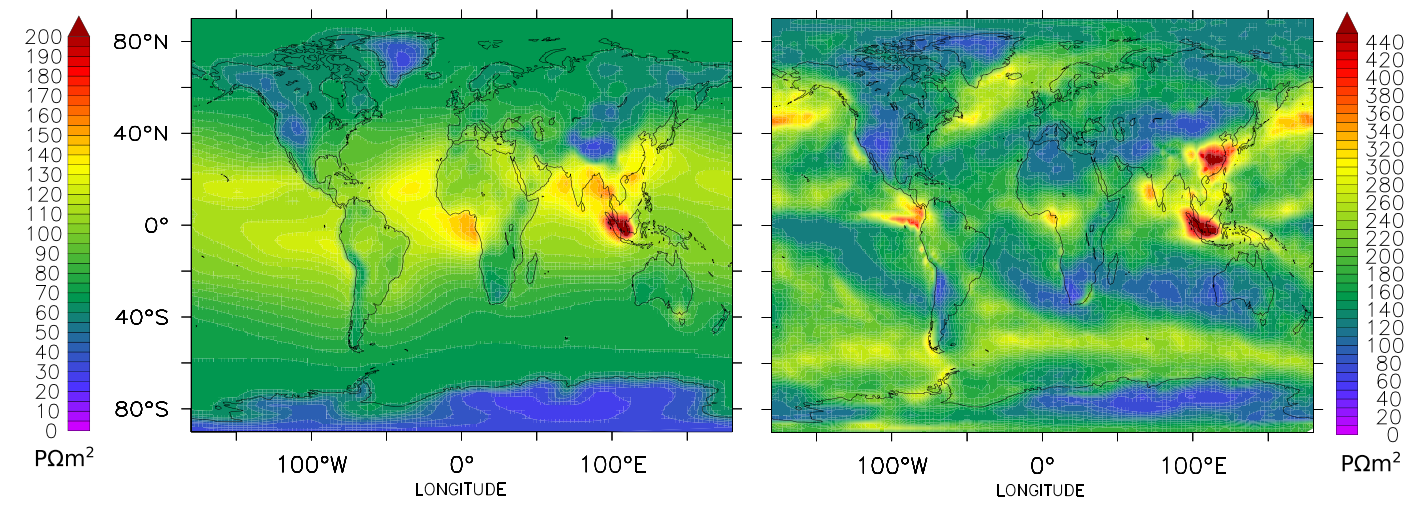

Figure 7. Mean model column resistance $\left(\mathrm{P} \Omega \mathrm{m}^{2}\right)$ for a single model year, (left) disregarding clouds and (right) including cloud influence. 


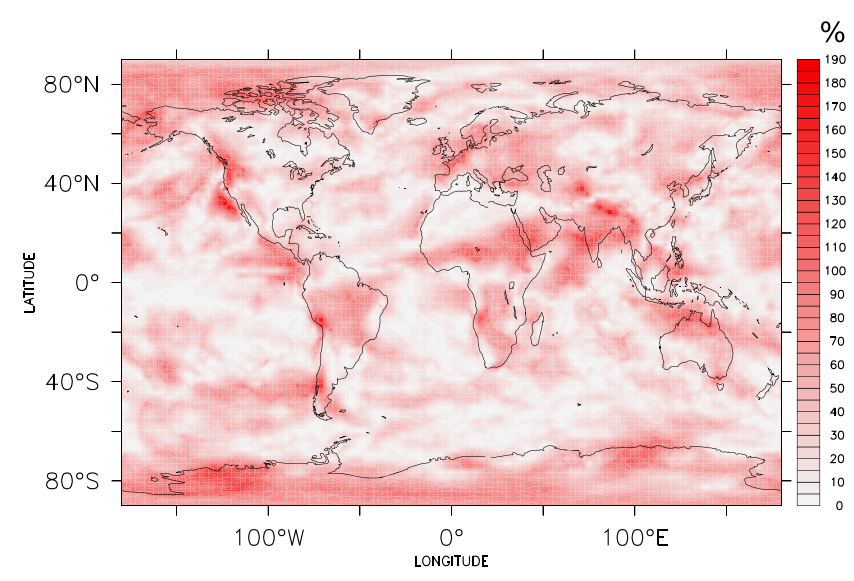

Figure 8. Amplitude of the column resistance seasonal cycle (difference between June-July-August and DecemberJanuary-February) in percent of local mean column resistance.

Northern Hemisphere summer, is found. Taking into account ion loss by aerosol particles (blue line) leads to intra-annual variations of approximately $9 \Omega$, resulting from the intraannual variations of the aerosol distribution. The latter is a result of variations in vertical transport, most dominantly through the Asian monsoon [Vernier et al., 2011b; Randel et $a l ., 2010]$, and in aerosol emissions from the surface through anthropogenic and natural activities.

[46] When clouds are also taken into account, total resistance further increases (black line) and inherits the cloud cover variability on a time scale of days to weeks. In addition, the seasonal variability has increased to $25 \Omega$. Therefore, the model shows a similar contribution to seasonal variability from clouds and aerosol.

[47] Both hemispheres show an increase in total resistance in the respective summer (purple: Northern Hemisphere, green: Southern Hemisphere) because of the cloud cover seasonal variation, but in the Northern Hemisphere the summer increase of $120 \Omega$ dominates the Southern Hemisphere winter decrease of $30 \Omega$ from March to July, effectively leaving the Northern Hemisphere summer to dominate the global total resistance variation.

[48] Currently, only variations in current source strength, which are mostly related to thunderstorm activity, are considered in discussions of intra-annual variations of the Carnegie curve and other Earth-ionosphere potential difference measurements [see, e.g., Williams, 2009; Blakeslee et al., 2012, and references therein]. However, due to Ohm's law, changes in global resistance would also lead to changes in the potential difference if a constant current source is assumed. It remains to be determined if the intraannual global resistance variations presented here could also significantly contribute to the observed potential difference changes.

[49] The influence of sources of other conductivity variability on total resistance can also be quantified from the model simulations. The annual mean model total resistance is $5 \Omega$ smaller at solar minimum (i.e., GCR maximum) compared to solar average conditions and $5 \Omega$ higher at solar maximum (i.e., GCR minimum). This is somewhat smaller than the variation of approximately $\pm 7 \Omega$ reported by TZ06 during low volcanic activity. During the January 2005 solar proton event, model total resistance decreased by up to $2 \Omega$, and without radon total resistance is smaller by $7 \Omega$. Additionally, temperature dependence of the ion-ion recombination rate and ion mobility lead to a small global average temperature dependence of total resistance. A warming of $5 \mathrm{~K}$ increases total resistance by approximately $1 \Omega$.

[50] Previous discussions, e.g., by TZ06, have suggested strong effects of volcanic emissions on stratospheric conductivity, with reductions of up to 3 orders of magnitude for high volcanic activity such as during the months after the Mount Pinatubo eruption of 1991. TZ06 based their results on the assumption of an ultrafine particle layer at $40 \mathrm{~km}$, centered on the poles, created by transport of light particles from the equatorial to polar regions via the BrewerDobson circulation. Observations show that this assumption is not realistic [English et al., 2013]. Here volcanic aerosol emissions, their transport, and microphysics are treated selfconsistently. As described in section 2, the simulation performed in this study includes enhanced background volcanic activity from 2006 but no colossal eruptions [Neely et al., 2013]. The difference in conductivity between the moderate volcanic and no volcanic aerosol inclusion is shown in Figure 10 as a percent change from the simulation without

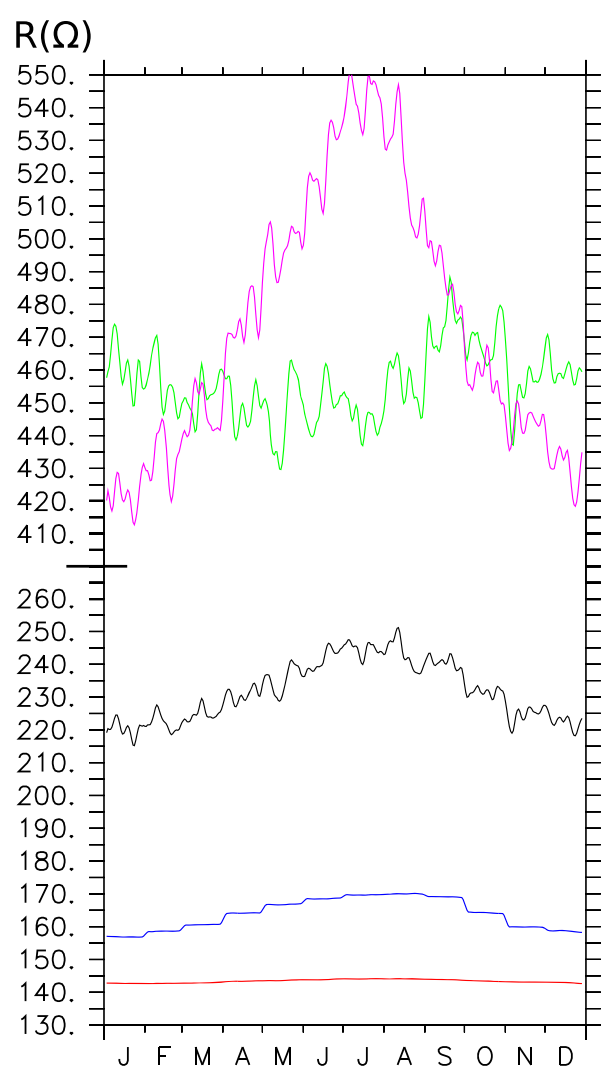

Figure 9. Intra-annual variations of total resistance. Global mean, taking into account all ion sources and sinks (black). Global mean, neglecting aerosol and clouds (red). Global mean, neglecting clouds (blue). Northern Hemisphere mean (seasonal variation) (purple). Southern Hemisphere mean (seasonal variation) (green). 


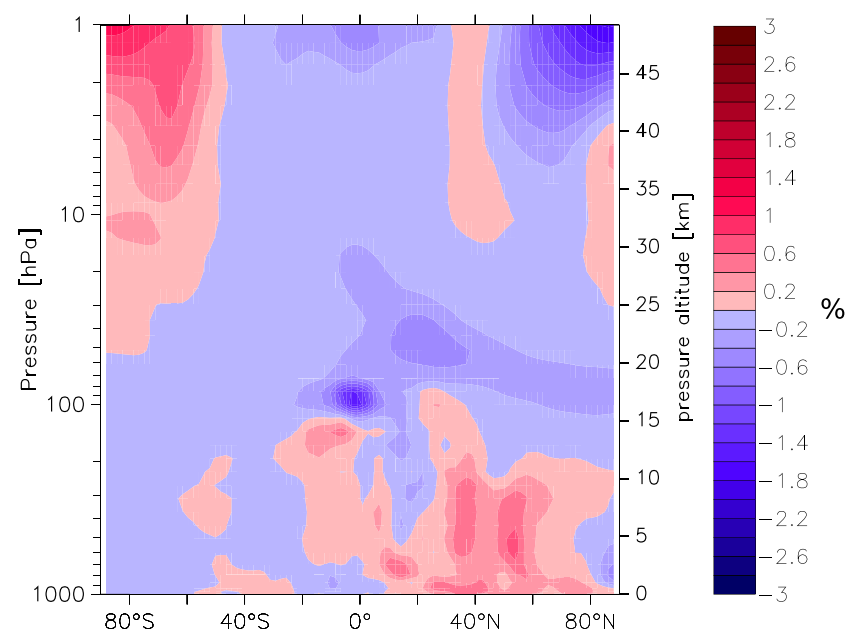

Figure 10. Percentage change in conductivity, averaged over one model year, due to moderate volcanic aerosol contributions to aerosol ion loss. Cloud contributions to ion loss are neglected.

volcanic aerosol. For the Northern Hemisphere, middle and upper polar stratosphere conductivity is reduced by up to $3 \%$. Note that this is a very small change in conductivity compared to the reductions of at least 1 order of magnitude estimated by TZ06 for a colossal volcanic aerosol loading. It appears unlikely that the differences in conductivity are due to the difference in moderate volcanic aerosol emission alone. In the Southern Hemisphere, conductivity increases due to the decrease in aerosol number density in this region, which is a result of particle coagulation and a shift to fewer but bigger particles. Further studies using larger volcanic eruptions such as those from Mount Pinatubo will be conducted and compared to the previous results of TZ06.

\subsection{Evaluation}

[51] In the following, a variety of published conductivity or resistance measurements are used to evaluate model performance. A direct comparison with the model results from TZ06 and ZT10 is not presented here. The parameterizations for GCRs, ion-ion recombination, and mobility are identical to TZ06, so a comparison does not appear useful to the reader, whereas input data sets especially for aerosol number density, ${ }^{222} \mathrm{Rn}$, and clouds have been validated independently by the authors of these data sets (see section 2) and thus represent a more comprehensive approach.

[52] Conductivity is usually measured using the Gerdien condenser technique or inferred from current density and electric field measurements. Such data have been gathered, e.g., on balloon flights since the early twentieth century [Everling and Wigand, 1921; Rosen and Hofmann, 1981, 1988] and recently on aircraft field campaigns [Mach et al., 2009, 2010, 2011].

[53] A valuable comparison of conductivity and other measurement techniques and instruments was performed in Laramie, Wyoming, and is presented by Rosen et al. [1982]. The observed positive ion conductivity profiles from $30 \mathrm{July}$ 1978 are reproduced here in Figure 11 (their Figure 2), with the model conductivity results for the same model day included (red line), including error bars for the range of model results for July and August, as well as possible aerosol variability. There is a very good match in the qualitative behavior of the measurements and the model results. The ${ }^{222} \mathrm{Rn}$-induced enhancement of conductivity near the surface is reproduced, as well as the different gradients in the upper troposphere and stratosphere. Except for the upper troposphere, there is also very good quantitative agreement. The largest uncertainty in the model comes from the aerosol and temperature distribution, which likely explain the deviations from the measurements between 300 and $400 \mathrm{hPa}$. Aerosol uncertainties most notably include the differences in sulfate aerosol loading from moderate volcanic activity and anthropogenic emissions of sulfur dioxide during this time. Note that the flights were performed on a clear day without clouds, and therefore the model was assumed to have no clouds for this location also.

[54] Mach et al. [2009] have performed conductivity measurements on board aircraft. The conductivity variation for an ER-2 flight on 19 September 2001, taken from their paper, is shown in Figure 12 (blue points, gray line). The mean flight altitude was $20 \mathrm{~km}$, ranging between 19.75 and $20.10 \mathrm{~km}$, and the flight direction was predominantly northbound, starting at $81.2^{\circ} \mathrm{W}, 24.3^{\circ} \mathrm{N}$ and ending at $80.8^{\circ} \mathrm{W}$, $25.2^{\circ} \mathrm{N}$. The red lines and shaded area in Figure 12 depict the model conductivity for the same day of year, for a longitude of $81.0^{\circ} \mathrm{W}$. The time axis was substituted with a latitude axis using the flight latitudes region. The model data were interpolated onto a very high vertical resolution, such that

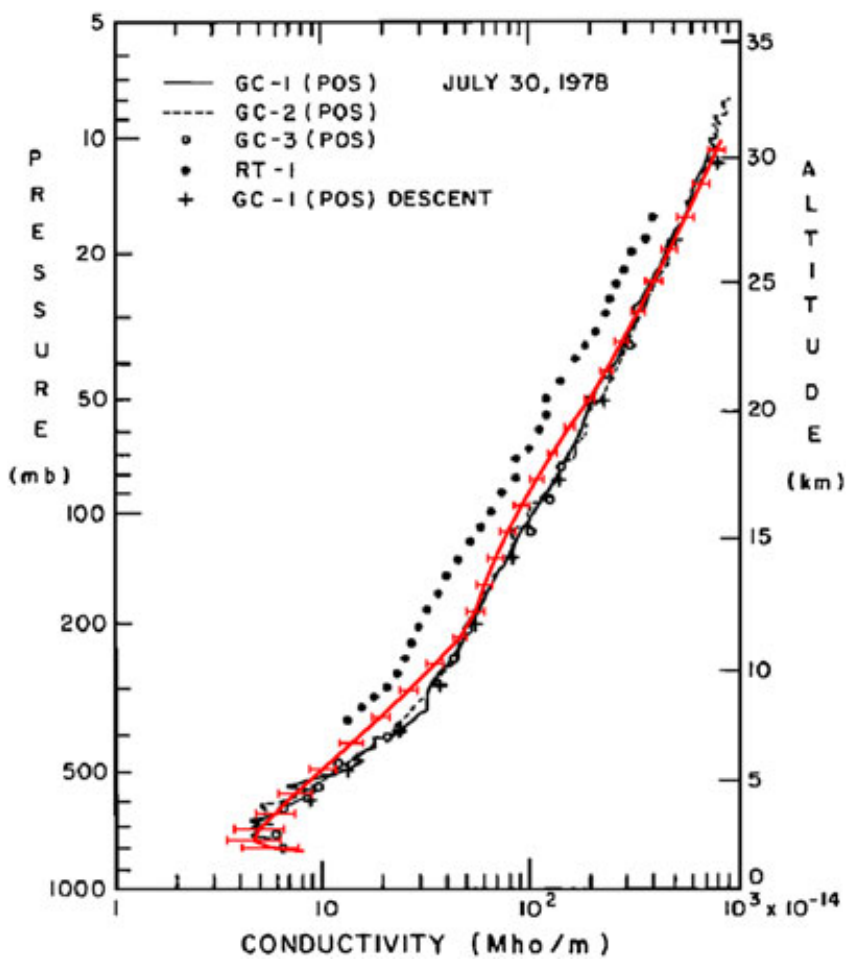

Figure 11. Conductivity measurements from various instruments (black lines and points) and model results (red line) from 30 July 1978 for the same location. The error bars show the range of model results for July and August and for aerosol variability. For details on the instruments, see Rosen et al. [1982]. 
the upper and lower red lines correspond to the maximum and minimum altitudes of the aircraft, respectively, during the flight leg. The small model conductivity increase toward higher latitudes is due to the GCR geomagnetic latitude variation as discussed above.

[55] Both the measurements and the model show a mean conductivity of approximately $2.8 \mathrm{pS} \mathrm{m}^{-1}$, with the measurements lying almost entirely in the model range. The GCR increase with latitude along the flight has a small effect on conductivity and cannot explain the increase of observed conductivity with time. However, the flight altitude changes by up to $350 \mathrm{~m}$ during that period, which corresponds to a change of conductivity by up to $0.25 \mathrm{pS} \mathrm{m}^{-1}$, indicating that altitude variations cause the observed conductivity increase.

[56] During a solar proton event, Kokorowski et al. [2006] have shown a significant increase in conductivity in the polar stratosphere as expected from the increased ionization rates from the precipitating energetic particles. The authors presented measurements from a MINIS (MINIature Spectrometer) balloon flight at approximately $32 \mathrm{~km}$ altitude in the southern polar cap area $\left(70.9^{\circ} \mathrm{S}, 10.9^{\circ} \mathrm{W}\right.$ to $71.4^{\circ} \mathrm{S}$ and $21.5^{\circ} \mathrm{W}$ ) for the solar proton event on 20 January 2005 . The ionization rates from AIMOS (see section 2 and Wissing and Kallenrode [2009]) for the same day and the balloon flight altitude are depicted in Figure 13. The black squares show the start and end location of the MINIS flight, indicating that the balloon was flying near the edge of the area impacted by the particle precipitation. Figure $2 \mathrm{a}$ of Kokorowski et al. [2006], reproduced here as the background of Figure 13 (bottom), shows the measured conductivity increase matching the onset of the event. The average model results for the same time period are overlayed in red; the error bars indicate the range of values for the measurement area $70 \pm 4^{\circ} \mathrm{N}, 16 \pm 10^{\circ} \mathrm{W}, 32 \pm 1 \mathrm{~km}$. The large latitudinal gradient in the flight region leads to a large difference between the model minimum and maximum conductivity. However, the measurements are almost entirely bounded by the model extrema before and during the solar proton event as well as in the recovery phase, giving confidence in the applied modeling approach.

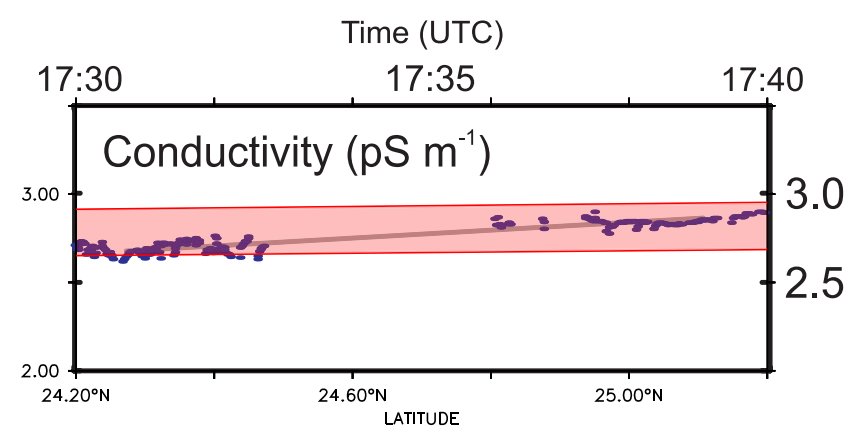

Figure 12. Conductivity measurements from the CAMEX4 campaign ER-2 aircraft flight on 19 September 2001 from $24.3^{\circ} \mathrm{N}, 81.2^{\circ} \mathrm{W}$ to $25.2^{\circ} \mathrm{N}$, and $80.8^{\circ} \mathrm{W}$ (blue points and grey line), and model results (red) for the same day of year and a path along $81.0^{\circ} \mathrm{W}$ and the indicated latitudes. The region shows the altitude range $19.75-20.10 \mathrm{~km}$. For details on the measurements, see Mach et al. [2009].
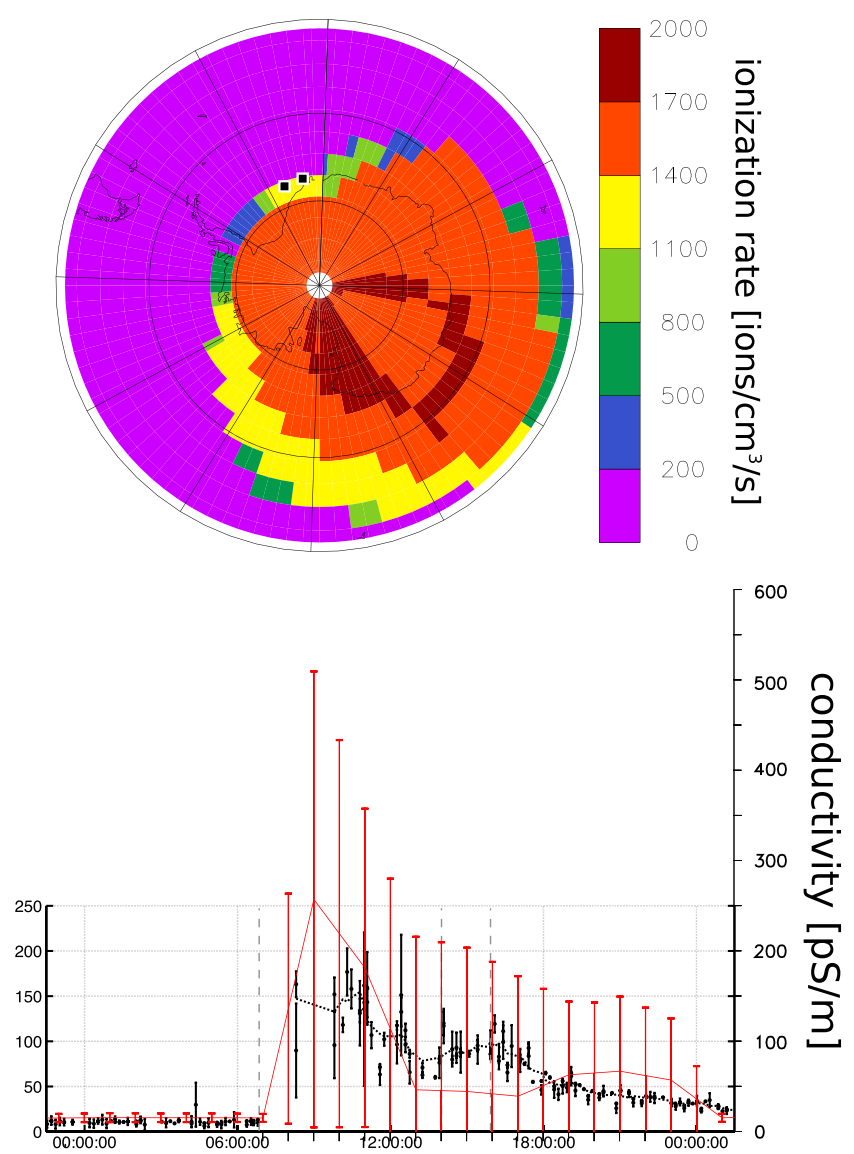

Figure 13. (top) Average ionization rates for 20 January 2005 from AIMOS; the black squares show the start and end location of the MINIS flight. (bottom) MINIS balloon flight conductivity measurements (black) from 20 January 2005 over Antarctica at $30 \mathrm{~km}$ altitude, taken from Kokorowski et al. [2006], and model conductivity (red) for the same geographical and altitudinal region, using the AIMOS ionization rates. Error bars indicate the range of model conductivity for this area.

\section{Summary and Conclusions}

[57] Due to the various sources and sinks of ions, linking sciences from the solar system, the middle and lower atmosphere down to the boundary layer and surface, a comprehensive Earth system model is required for an accurate description of conductivity. Here a new module for the calculation of electrical conductivity was added to CESM1(WACCM) to be able to reach a more detailed description and increase our understanding of the parameters that control conductivity.

[58] Using the enhanced CESM1 system, a detailed picture of conductivity was derived for the first time. Satisfying agreement between the model results, measurements, and previous model studies gives confidence in our current understanding of the mean conductivity aspects and the application to this model. The detailed treatment of all major aspects also leads to a new finding concerning total resistance, for which the model shows an intra-annual cycle. Seasonal aerosol and cloud cover variability is stronger in 
the Northern Hemisphere than in the Southern Hemisphere and thus leads to global intra-annual variations.

[59] For further studies of the GEC, the conductivity output of this model will be employed in GEC models solving for electric potential, currents, and electric fields. It is very likely that the variability of the conductivity distributions shown here will strongly affect current flow in the atmosphere. Conductivity distributions will be one of several factors, also including the thunderstorm source distributions and magnetospheric as well as ionospheric variations, that determine potential, currents, and electric field distributions, yet their individual contributions can only be determined in a full GEC model.

[60] Future work to consolidate the presented findings on conductivity, and to further test our understanding of the involved processes, will include the description of tropospheric/stratospheric ion chemistry in CESM1(WACCM) and to parametrize ion mobility depending on the ion size. Further possible studies also include highly disturbed conditions, such as polar stratospheric clouds, colossal volcanic eruptions, or nuclear explosions as shown by Israelsson and Knudsen [1986], who demonstrated the additional ionization's impact on conductivity and related GEC parameters. This model offers, for the first time, the possibility of simulating and analyzing the imposed effects of such events in much more detail.

[61] Acknowledgments. This work was supported by NSF Award AGS-1135446 to the University of Colorado under the Frontiers in Earth System Dynamics Program (FESD). The CESM project is supported by the National Science Foundation and the Office of Science (BER) of the U.S. Department of Energy. The National Center for Atmospheric Research is sponsored by the National Science Foundation. We would like to acknowledge high-performance computing support from Yellowstone [Computational and Information Systems Laboratory, 2012]. R. R. Neely is funded by the NSF in NCAR's Advanced Study Program. We have used the Ferret program (http://www.ferret.noaa.gov) from NOAA's Pacific Marine Environmental Laboratory for creating some of the graphics in this paper. The AIMOS data were provided by Jan-Maik Wissing/University of Osnabrück (http://aimos.physik.uos.de).

\section{References}

Ackermann, M., et al. (2013), Detection of the characteristic pion-decay signature in supernova remnants, Science, 339, 807-811, doi:10.1126/ science. 1231160.

Aplin, K. L., R. G. Harrison, and M. J. Rycroft (2008), Investigating Earth's atmospheric electricity: A role model for planetary studies, Space Sci. Rev., 137, 11-27, doi:10.1007/s11214-008-9372-x.

Bardeen, C. G., O. B. Toon, E. J. Jensen, D. R. Marsh, and V. L. Harvey (2008), Numerical simulations of the three-dimensional distribution of meteoric dust in the mesosphere and upper stratosphere, J. Geophys. Res., 113, D17202, doi:10.1029/2007JD009515.

Bardeen, C. G., O. B. Toon, E. J. Jensen, M. E. Hervig, C. E. Randall, S. Benze, D. R. Marsh, and A. Merkel (2010), Numerical simulations of the three-dimensional distribution of polar mesospheric clouds and comparisons with Cloud Imaging and Particle Size (CIPS) experiment and the Solar Occultation For Ice Experiment (SOFIE) observations, J. Geophys. Res., 115, D10204, doi:10.1029/2009JD012451.

Bazilevskaya, G. A., et al. (2008), Cosmic ray induced ion production in the atmosphere, Space Sci. Rev., 137, 149-173, doi:10.1007/s11214-0089339-y.

Blakeslee, R. J., D. M. Mach, M. G. Bateman, and J. C. Bailey (2012), Seasonal variations in the lightning diurnal cycle and implications for the global electric circuit, Atmos. Res., 72, 376-381, doi:10.1016/j.atmosres.2012.09.023.

Computational and Information Systems Laboratory (2012), Yellowstone: IBM iDataPlex System (NCAR Community Computing), Boulder, CO: National Center for Atmos. Res., http://n2t.net/ark:/85065/d7wd3xhc.

English, J. M., O. B. Toon, M. J. Mills, and F. Yu (2011), Microphysical simulations of new particle formation in the upper troposphere and lower stratosphere, Atmos. Chem. Phys., 11, 9303-9322, doi:10.5194/acp-119303-2011.
English, J. M., O. B. Toon, and M. J. Mills (2013), Microphysical simulations of large volcanic eruptions: Pinatubo and Toba, J. Geophys. Res. Space Phys., 118, 1880-1895, doi:10.1002/J. Geophys. Res.d.50196.

Everling, E., and A. Wigand (1921), Spannungsgefälle und vertikaler Leitungsstrom in der freien Atmosphäre, nach Messungen bei Hochfahrten im Freiballon, Ann. Phys.-Berlin, 371, 261-282, doi:10.1002/andp.19213712004.

Fan, T., and O. B. Toon (2011), Modeling sea-salt aerosol in a coupled climate and sectional microphysical model: Mass, optical depth and number concentration, Atmos. Chem. Phys., 11, 4587-4610, doi:10.5194/acp-11-4587-2011.

Funke, B., et al. (2011), Composition changes after the "Halloween" solar proton event: The High Energy Particle Precipitation in the Atmosphere (HEPPA) model versus MIPAS data intercomparison study, Atmos. Chem. Phys., 11, 9089-9139, doi:10.5194/acp-11-9089-2011.

Gringel, W., J. M. Rosen, and D. J. Hoffman (1986), Electrical structure from 0 to 30 kilometers, in The Earth's Electrical Environment, edited by E. P. Krider and R. G. Roble, pp. 166-182, Natl. Acad. Press, Washington, D. C.

Harrison, R. G., K. L. Aplin, and M. J. Rycroft (2010), Atmospheric electricity coupling between earthquake regions and the ionosphere, J. Atmos. Sol. Terr. Phys., 72, 376-381, doi:10.1016/j.jastp.2009. 12.004.

Hays, P. B., and R. G. Roble (1979), A quasi-static model of global atmospheric electricity. I-The lower atmosphere, J. Geophys. Res., 84, 3291-3305, doi:10.1029/JA084iA07p03291.

Hoppel, W. A. (1985), Ion-aerosol attachment coefficients, ion depletion, and the charge distribution on aerosols, J. Geophys. Res., 90, 5917-5923, doi:10.1029/JD090iD04p05917.

Hoppel, W. A., R. V. Anderson, and J. C. Willett (1986), Atmospheric electricity in the planetary boundary layer, in The Earth's Electrical Environment, edited by E.P. Krider and R.G. Roble, pp. 149-165, Natl. Acad. Press, Washington, D. C.

Israelsson, S., and E. Knudsen (1986), Effects of radioactive fallout from a nuclear power plant accident on electrical parameters, J. Geophys. Res., 91, 11,909-11,910, doi:10.1029/JD091iD11p11909.

Jackman, C. H., and R. D. McPeters (2004), The effect of solar proton events on ozone and other constituents, in Solar Variability and Its Effects on Climate, Geophysical Monograph, vol. 141, edited by J. M. Pap et al., pp. 305-319, American Geophysical Union, Washington, D. C.

Jackman, C. H., et al. (2008), Short- and medium-term atmospheric constituent effects of very large solar proton events, Atmos. Chem. Phys., 8, 765-785.

Jöckel, P., A. Kerkweg, A. Pozzer, R. Sander, H. Tost, H. Riede, A. Baumgaertner, S. Gromov, and B. Kern (2010), Development cycle 2 of the Modular Earth Submodel System (MESSy2), Geosci. Model Dev., 3, 717-752, doi:10.5194/gmd-3-717-2010.

Kay, J. E., et al. (2012), Exposing Global cloud biases in the Community Atmosphere Model (CAM) using satellite observations and their corresponding instrument simulators, J. Clim., 25, 5190-5207, doi:10.1175/JCLI-D-11-00469.1.

Kokorowski, M., et al. (2006), Rapid fluctuations of stratospheric electric field following a solar energetic particle event, Geophys. Res. Lett., 33, L20105, doi:10.1029/2006GL027718.

Krider, E. P. (1986), The electrical structure of thunderstorms, in The Earth's Electrical Environment, edited by E. P. Krider and R. G. Roble, pp. 90-113, Natl. Acad. Press, Washington, D. C.

Lamarque, J.-F., et al. (2012), CAM-chem: Description and evaluation of interactive atmospheric chemistry in the community Earth system model, Geosci. Model Dev., 5, 369-411, doi:10.5194/gmd-5-369-2012.

Leblanc, F., K. L. Aplin, Y. Yair, R. G. Harrison, J. P. Lebreton, and M. Blanc (2008), Planetary Atmospheric Electricity, Springer, New York, N. Y., doi:10.1007/978-0-387-87664-1.

MacGorman, D. R., and W. D. Rust (1998), The Electrical Nature of Storms, Oxford Univ. Press, New York.

Mach, D. M., R. J. Blakeslee, M. G. Bateman, and J. C. Bailey (2009), Electric fields, conductivity, and estimated currents from aircraft overflights of electrified clouds, J. Geophys. Res., 114, D10204, doi:10.1029/2008JD011495.

Mach, D. M., R. J. Blakeslee, M. G. Bateman, and J. C. Bailey (2010), Comparisons of total currents based on storm location, polarity, and flash rates derived from high-altitude aircraft overflights, J. Geophys. Res., 115, D03201, doi:10.1029/2009JD012240.

Mach, D. M., R. J. Blakeslee, and M. G. Bateman (2011), Global electric circuit implications of combined aircraft storm electric current measurements and satellite-based diurnal lightning statistics, J. Geophys. Res., 116, D05201, doi:10.1029/2010JD014462.

Marsh, D. R., M. J. Mills, D. E. Kinnison, J. Lamarque, N. Calvo, and L. M. Polvani (2013), Climate change from 1850 to 2005 simulated in CESM1(WACCM), J. Clim., doi:10.1175/JCLI-D-12-00558.1. 
Matichuk, R. I., P. R. Colarco, J. A. Smith, and O. B. Toon (2008), Modeling the transport and optical properties of smoke plumes from South American biomass burning, J. Geophys. Res., 113, D07208, doi:10.1029/2007JD009005.

Meehl, G. A., W. M. Washington, J. M. Arblaster, A. Hu, H. Teng, J. E. Kay, A. Gettelman, D. M. Lawrence, B. M. Sanderson, and W. G. Strand (2013), Climate change projections in CESM1(CAM5) compared to CCSM4, J. Clim., doi:10.1175/JCLI-D-12-00572.1.

Morrison, H., and A. Gettelman (2008), A new two-moment bulk stratiform cloud microphysics scheme in the Community Atmosphere Model, Version 3 (CAM3). Part I: Description and numerical tests, J. Clim., 21, 3642-3659, doi:10.1175/2008JCLI2105.1.

Neale, R. B., J. Richter, S. Park, P. H. Lauritzen, S. J. Vavrus, P. J. Rasch, and M. Zhang (2013), The mean climate of the Community Atmosphere Model (CAM4) in forced SST and fully coupled experiments, J. Clim., 26, 5150-5168, doi:10.1175/JCLI-D-12-00236.1.

Neely, R. R. III, J. M. English, O. B. Toon, S. Solomon, M. Mills, and J. P. Thayer (2011), Implications of extinction due to meteoritic smoke in the upper stratosphere, Geophys. Res. Lett., 38, L24808, doi:10.1029/2011GL049865.

Neely, R. R. III, et al. (2013), Recent anthropogenic increases in SO2 from Asia have minimal impact on stratospheric aerosol, Geophys. Res. Lett., 40, 1-6, doi:10.1002/grl.50263.

Neher, H. V. (1967), Cosmic-ray particles that changed from 1954 to 1958 to 1965, J. Geophys. Res., 72, 1527-1539, doi:10.1029/ JZ072i005p01527.

Neher, H. V. (1971), Cosmic rays at high latitudes and altitudes covering four solar maxima, J. Geophys. Res., 76, 1637-1651, doi:10.1029/ JA076i007p01637.

Nicoll, K. (2012), Measurements of atmospheric electricity aloft, Surv. Geophys., 33, 991-1057, doi:10.1007/s10712-012-9188-9.

Odum, J. R., T. Hoffmann, F. Bowman, D. Collins, R. C. Flagan, and J. H. Seinfeld (1996), Gas/particle partitioning and secondary organic aerosol yields, Environ. Sci. Technol., 30, 2580-2585, doi:10.1021/ es950943+.

Odzimek, A., M. Lester, and M. Kubicki (2010), EGATEC: A new high-resolution engineering model of the global atmospheric electric circuit-Currents in the lower atmosphere, J. Geophys. Res., 115, D18207, doi:10.1029/2009JD013341.

Pankow, J. F. (1994), An absorption model of gas/particle partitioning of organic compounds in the atmosphere, Atmos. Environ., 28(2), 185-188, doi:10.1016/1352-2310(94)90093-0.

Pasko, V. P. (2010), Recent advances in theory of transient luminous events, J. Geophys. Res., 115, A00E35, doi:10.1029/2009JA014860.

Pruppacher, H. R., and J. D. Klett (1997), Microphysics of Clouds and Precipitation, 2nd ed., Kluwer Acad., Dordrecht, The Netherlands.

Randel, W. J., M. Park, L. Emmons, D. Kinnison, P. Bernath, K. A. Walker, C. Boone, and H. Pumphrey (2010), Asian monsoon transport of pollution to the stratosphere, Science, 328, 611-613, doi:10.1126/ science. 1182274 .

Roble, R. G., and P. B. Hays (1979a), A quasi-static model of global atmospheric electricity. II-Electrical coupling between the upper and lower atmosphere, J. Geophys. Res., 84, 7247-7256, doi:10.1029/JA084iA12p07247.

Roble, R. G., and P. B. Hays (1979b), Electrical coupling between the upper and lower atmosphere, in Solar-Terrestrial Influences on Weather and Climate, edited by B. M. McCormac and T. A. Seliga, pp. 233-241, D. Reidel Publ. Co., Dordrecht, Holland.

Rosen, J. M., and D. J. Hofmann (1981), Balloon-borne measurements of electrical conductivity, mobility, and the recombination coefficient, $J$. Geophys. Res., 86, 7406-7410, doi:10.1029/JC086iC08p07406.

Rosen, J. M., and D. J. Hofmann (1988), A search for large ions in the stratosphere, J. Geophys. Res., 93, 8415-8422, doi:10.1029/ JD093iD07p08415.

Rosen, J. M., D. J. Hofmann, W. Gringel, J. Berlinski, S. Michnowski, Y. Morita, T. Ogawa, and D. Olson (1982), Results of an international workshop on atmospheric electrical measurements, J. Geophys. Res., 87, 1219-1224, doi:10.1029/JC087iC02p01219.

Rosen, J. M., D. J. Hofmann, and W. Gringel (1985), Measurements of ion mobility to $30 \mathrm{~km}$, J. Geophys. Res., 90, 5876-5884, doi:10.1029/JD090iD04p05876.
Rycroft, M. J., and R. G. Harrison (2012), Electromagnetic atmosphereplasma coupling: The global atmospheric electric circuit, Space Sci. Rev., 168, 363-384, doi:10.1007/s11214-011-9830-8.

Rycroft, M. J., and A. Odzimek (2009), The impact of lightning flashes and sprites on the Earth's global electric circuit: An overview of recent modeling results, in American Institute of Physics Conference Series, vol. 1118, edited by N. B. Crosby, T.-Y. Huang, and M. J. Rycroft, pp. 124-135, American Institute of Physics, Corte, France, doi:10.1063/1.3137704

Rycroft, M. J., and A. Odzimek (2010), Effects of lightning and sprites on the ionospheric potential, and threshold effects on sprite initiation, obtained using an analog model of the global atmospheric electric circuit, J. Geophys. Res., 115, A00E37, doi:10.1029/2009JA014758.

Rycroft, M. J., A. Odzimek, N. F. Arnold, M. Füllekrug, A. Kułak, and T. Neubert (2007), New model simulations of the global atmospheric electric circuit driven by thunderstorms and electrified shower clouds: The roles of lightning and sprites, J. Atmos. Sol. Terr. Phys., 69, 2485-2509, doi:10.1016/j.jastp.2007.09.004.

Rycroft, M. J., K. A. Nicoll, K. L. Aplin, and R. Giles Harrison (2012), Recent advances in global electric circuit coupling between the space environment and the troposphere, J. Atmos. Sol. Terr. Phys., 90, 198-211, doi:10.1016/j.jastp.2012.03.015.

Schery, S. D., and M. A. Wasiolek (1998), Modelling radon flux from the Earth's surface, in Radon and Thoron in the Human Environment, Proceedings of the 7th Tohwa University International Symposium, edited by A. Katase and M. Shimo, pp. 207-217, World Scientific, Singapore.

Singh, D. K., R. P. Singh, and A. K. Kamra (2004), The electrical environment of the Earth's atmosphere: A review, Space Sci. Rev., 113, 375-408, doi:10.1023/B:SPAC.0000046747.32359.d8.

Su, L., and O. B. Toon (2009), Numerical simulations of Asian dust storms using a coupled climate-aerosol microphysical model, J. Geophys. Res., 114, D14202, doi:10.1029/2008JD010956.

Su, L., and O. B. Toon (2011), Saharan and Asian dust: Similarities and differences determined by CALIPSO, AERONET, and a coupled climate-aerosol microphysical model, Atmos. Chem. Phys., 11, 3263-3280, doi:10.5194/acp-11-3263-2011.

Tinsley, B. A., and L. Zhou (2006), Initial results of a global circuit model with variable stratospheric and tropospheric aerosols, J. Geophys. Res. 111, D16205, doi:10.1029/2005JD006988.

Toon, O. B., R. P. Turco, P. Hamill, C. S. Kiang, and R. C. Whitten (1979), A one-dimensional model describing aerosol formation and evolution in the stratosphere: II. Sensitivity studies and comparison with observations, J. Atmos. Sci., 36, 718-736, doi:10.1175/15200469(1979)036<0718:AODMDA>2.0.CO;2.

Toon, O. B., R. P. Turco, D. Westphal, R. Malone, and M. S. Liu (1988), A multidimensional model for aerosols-Description of computational analogs, J. Atmos. Sci., 45, 2123-2143, doi:10.1175/15200469(1988)045<2123:AMMFAD>2.0.CO;2.

Turco, R. P., P. Hamill, O. B. Toon, R. C. Whitten, and C. S. Kiang (1979), A one-dimensional model describing aerosol formation and evolution in the stratosphere: I. Physical processes and mathematical analogs, J. Atmos. Sci., 36, 699-717, doi:10.1175/15200469(1979)036<0699:AODMDA > 2.0.CO;2.

Usoskin, I. G., K. Alanko-Huotari, G. A. Kovaltsov, and K. Mursula (2005), Heliospheric modulation of cosmic rays: Monthly reconstruction for 1951-2004, J. Geophys. Res., 110, A12108, doi:10.1029/2005JA011250.

Vernier, J.-P., et al. (2011a), Major influence of tropical volcanic eruptions on the stratospheric aerosol layer during the last decade, Geophys. Res. Lett., 38, L12807, doi:10.1029/2011GL047563.

Vernier, J.-P., L. W. Thomason, and J. Kar (2011b), CALIPSO detection of an Asian tropopause aerosol layer, Geophys. Res. Lett., 38, L07804, doi:10.1029/2010GL046614.

Williams, E. R. (2009), The global electrical circuit: A review, Atmos. Res., $91,140-152$.

Wissing, J. M., and M.-B. Kallenrode (2009), Atmospheric Ionization Module Osnabrück (AIMOS): A 3-D model to determine atmospheric ionization by energetic charged particles from different populations, J. Geophys. Res., 114, A06104, doi:10.1029/2008JA013884.

Zhou, L., and B. A. Tinsley (2010), Global circuit model with clouds, J. Atmos. Sci., 67, 1143-1156, doi:10.1175/2009JAS3208.1. 